\section{Technical Efficiency in Public Health Facilities in Meru County: Dea Analysis}

\section{Anthony Juma Makheti*}

School of Economics, University of Nairobi, University Way, Nairobi, Kenya

*Corresponding author: Anthony Juma Makheti, School of Economics, University of Nairobi, University Way, Nairobi, Kenya, Tel: +254728964806; E-mail: antonyjuma61@gmail.com

Received date: Sep 20, 2017; Accepted date: Oct 16, 2017; Published date: Oct 23, 2017

Copyright: ( 2017 Makheti AJ. This is an open-access article distributed under the terms of the Creative Commons Attribution License, which permits unrestricted use, distribution, and reproduction in any medium, provided the original author and source are credited.

\begin{abstract}
Background: Healthcare provision is one of the key strategic Development Goals to be achieved by the year 2030. Governments have directed a lot of financial resources towards this purpose in an effort to meet the threshold set out by the WHO to ensure provision of quality healthcare and access by all citizens.

Objectives: To measure the technical efficiency levels in the public health system in Meru County in Kenya and investigate determinants of the technical efficiencies among the Decision Making Units (DMUs).

Data analysis: Analysis reported in this paper is based on the data from Meru County health centres. It consisted of 17 Decision Making Units (DMUs) with inputs as clinical staff and other staff while outputs were maternal care visits and other visits. Dummy variables considered were; education, training, gender of head nurse and laboratory. Analysis was done by Data Envelopment Analysis (DEA).

Results: The analysis revealed that average technical efficiency in the sample was $45.2 \%$. This findings suggest that the existing health care services can be increased by up to $54.8 \%$ without providing additional resources to the frontline health facilities- a near replication of findings originally reported earlier. Tobit regression results show that gender of the facility manager and the availability of a laboratory at a facility are the main determinants of efficiency.

Conclusion and recommendation: Policies designed to improve health care delivery should focus on upgrading laboratory services and skills of facility heads, especially managerial abilities of female nurses. Efforts need to be directed towards enhancing efficiency such as training staff in management practices, maintenance of laboratory equipment, gender composition of staff should equally be considered. Focus on preventive healthcare such as regular check-ups would lower risks of severe or resistant cases that are difficult to treat in order to increase efficiency. Creation of conducive waiting and smooth flow of patient queues in the health facility would also increase technical efficiency of the facility.
\end{abstract}

Keywords: DEA; Health facilities; Tobit regression; Meru county

\section{Introduction}

There is an increased global attention on human health. The ballooning cost of public healthcare [1] due to emergency of complicated diseases [2-4], increased budgetary allocations to meet these challenges and given the global effort to improve quality of life and increase labour productivity, there is need to ensure efficient use of available resources in the health sector. Among the Sustainable Development Goals (SDGs) is provision of good quality healthcare to citizens of every country [2]. Thus most countries are racing against time to beat the 2030 dateline for universal provision of quality health care [5]. Kenya through the devolved function of the health sector has embarked on various strategies to enhance efficient and effective medical care to citizens. County governments are in upbeat drive to provide efficient quality healthcare at county levels. The promulgation of the New Constitution 2010 gave several powers to the county governments among them the provision and management of all the healthcare facilities, including the human resources both medical and public health in their respective counties [6]. Information on health care efficiency at the county level, especially at the frontline facilities (dispensaries and health centres) is key to Kenya achieving the health SDGs.

A study carried out in Kenya [7], found that healthcare is a necessary good. The study found that the per capita income elasticity of health care in Kenya is far below unity at 0.024 . From the findings, it is important that National Government in conjunction with County Governments establish cost effective policies to provide quality health care to all Kenyans, irrespective of their wealth levels.

Many studies have been carried out regarding health status in Kenya, but little has been done on how efficiently county governments contribute towards achieving the Strategic Development Goals on health. This research seeks to close the missing link on information about efficiency of the public healthcare services provision in Kenya, especially at the frontline level of the health system.

Since the enactment of the New Constitution 2010, county governments in Kenya took over the running of the healthcare facilities within their respective counties. There is need to document scientifically the facts regarding current levels of efficiency at health facilities with an aim of improving service delivery. This is important 
because of a rapid increase in demand for healthcare due to the growing population, high prevalence of diseases such as cancer, diabetes and high blood pressure. This study shows the extent to which one county government in Kenya is investing appropriately in the health sector to ensure effective and efficient health care delivery to citizens. The factors affecting efficiency levels are also investigated. The remainder of the paper is organized as follows. Section 2 reviews the relevant literature; the methodology is presented in Section 3; Section 4 presents and discusses study findings and Section 5 concludes.

\section{Background and Literature Review}

During the United Nations Millennium Summit in September 2000, world leaders set Millennium Development Goals (MDGs) to combat the world's ills among which Health was given priority to deal with diseases such as malaria and reverse child mortality rate by the year 2015. "All the member countries were tasked to create policies that support access to effective healthcare with special attention to the disadvantaged citizens". [8]. There is renewed effort to tackle health issues through the launch of Sustainable Development Goals (SDGs). It is clear that, for any country to realise steady economic development, a healthy labour force is paramount for both present and future needs. The health of society is crucial. Therefore the government should endeavour to increase both volume and quality of medical care without cost in proportion. This calls for efficient management of available resources to avoid wastage and minimise cost of health care.

There is an increasing global attention to health and effort is being made to break barriers to health care delivery. Developing countries continue to face serious challenges in provision of health care services to citizens. The Sub Saharan Africa has not escaped this trap despite enormous effort being made by most countries. Malaria deaths in Tanzania (Zanzibar) substantially dropped while in Uganda, maternal mortality dropped by more than half [9] Despite the effort, it was noted that life expectancy dropped by 2 years from 49.1 to 47.1 years. Further, most Africans still suffer from diseases relatively simple to prevent or treat. World leaders pay a lot of attention to health due to the deep understanding of the link between health and economic development.

Several barriers to effective healthcare have been identified among them being; inaccessibility to primary healthcare due to shortage of dispensaries and clinics, insufficient competent workforce, and operational weaknesses that prevent the system from functioning efficiently. Shortage of facilities, medical supplies, and skilled staff, absence of clean water all compromise effective and efficient healthcare system. There is need to increase funding, better management capabilities, better mind sets and behaviour to boost healthcare delivery among citizens.

Sub Saharan Africa suffers poor healthcare due to low infrastructural investment, and poor management of health facilities, shortage of drugs, overpriced services, inaccessibility and unqualified staff. It is important to note that due to low confidence in staff qualifications and competencies coupled with poor infrastructure and equipment, those with resources usually seek medical care from wellequipped but expensive private hospitals, leaving majority of citizens without proper care.

Further, misappropriation of medical funds escalate problems in medical healthcare. Majority of patients are given diagnostic services and left to search for drugs in commercial chemists elsewhere, this reduces survival chances as most patients do not afford the cost of drugs.

Equipment like diagnostic ultra sound machines, X- Ray, foetal monitors and effectively well stocked pharmacies, laboratories are not common in most Sub-county hospitals thus health workers rely on conventional diagnosis further putting patients in danger of misdiagnosis. Most advanced hospitals have adopted the Evidence Based dimension of care and treatment approach. This lowers risk of wrong prescription of drugs hence improve healthcare service provision and can lead to improved labour output.

The Kenyan government in their health policy 2014-2030 equally emphasized the need to operate efficiently given the limited budgetary allocations and burden of disease. The government recognizes that reasonable policies are in place but not effectively being implemented thus causing wastage [10]. This means there is need to establish the efficient levels of operation to cut down on wasteful expenditure in the health sector.

Efficiency is generally defined as a situation where there is usage of minimum amount of inputs to get a given level of output possible, such as number of patients treated over a given period of time. The growing demand for healthcare services and the limited funds to governments require that available resources be used efficiently. This includes utilisation of doctors, nurses, clinical officers, non-clinical staff, beds and the facilities available to ensure patients receive the best attention from the facility.

Efficiency is concerned with the relation between resource inputs such as labour, capital, equipment and the outputs such as number of patients treated or final health outcomes [10]. Efficiency and productivity go hand in hand and efficiency is a clear measure of productivity. There are four types of efficiency:

Allocative efficiency which has to do with distribution of healthcare services to the society. Productive efficiency or operational efficiency which is concerned with the best processes for delivering a given level of health services. Technical efficiency which is concerned with the best combination and use of inputs to deliver the best possible care [11].

Economic efficiency is the product of technical efficiency, productive and allocative efficiency where prices matter in the allocation of health inputs. Prices matter in the sense that efficiency is determined by comparing service benefits with its costs. The Kenya Health Policy Framework 2014-2030 emphasizes the application of principles of efficiency in service delivery [6].

The structure of the healthcare service delivery system in Kenya is hierarchical and has the following levels: level one is the community; level two comprises dispensaries; level three consists of health centres; level four has primary referral facilities; level five is made up of secondary referral facilities and finally level six has tertiary level facilities.

Government expenditure on healthcare is still poor at between $6 \%-8 \%$ of the financial budget [10]. Per capita health expenditure increased from $\$ 34$ in 2001/2002 to $\$ 42$ in 2009/2010, which remains below the WHO target of $\$ 64$. The policy further showed lack of essential tools, medical and non-medical supplies in health facilities, there was poor and unsafe working environment which contribute to low morale and productivity of workers. 
It has been found that nurses play a key role in boosting efficient and quality of care in hospitals. Scholars recommend a healthcare system that is safe, reliable, timely and patient-centred. There is also a need to control the escalating hospital costs which have increased significantly [12].

Many scholars have studied efficiency in health service provision. According to a study carried out on technical efficiency in public health centres in Ghana [13], of the 89 sampled health centres, $65 \%$ were found to be technically inefficient, and there was mass wastage of resources. The researcher adopted DEA approach and concentrated on variable returns to scale (VRS) due to data limitation.

Another study in Ghana showed that there was inefficiency and this prevented the country from achieving its health Millennium Development Goals [14]. The study used cross sectional survey of National Hospital Insurance Scheme accredited health facilities. The researchers collected data using the 'situational analysis' method. They used DEA to estimate technical efficiency levels and Tobit regression analysis was used to predict factors associated with efficiency levels. Results showed that only $31 \%$ of facilities were efficient. It was further noted that there was wastage of resources especially in urban areas.

A research carried out on equity and access to healthcare in Portugal by [15] found that long hospitalisation days consumed unnecessary hospital resources on patients with ambulatory care sensitive conditions. Further evidence on hospital inefficiency was demonstrated in Angola [11]. The research found that over $60 \%$ of recurrent budget of the ministry of health was spent on operations of fixed health facilities, ignoring the budgetary needs for mobile clinics. Nearly $61 \%$ of the hospitals studied were found to be inefficient. It was recommended that the affected hospitals increase their output or transfer staff to those with shortages to operate efficiently.

A study in Cameroon on Cameroonian health sector strategy found a technical efficiency level of 0.7098 [16]. The research established that urban facilities performed better than rural ones which was the opposite of findings in Ghana where wastage was more in urban than in rural facilities [17]. To measure relative efficiency of peripheral healthcare centers, they employed a model that relaxes the assumption of constant returns to scale and allows variable returns. The researchers found that efficiency was correlated with supervision, existence of management committees, qualifications of section heads, absenteeism, and age and location of facility.

Although there are several approaches to efficiency measurement; Most studies used DEA [18-21], and Stochastic Frontier Analysis (SFA); DEA is the most commonly used method because of its flexibility. The literature shows that most public health facilities in developing countries are operating inefficiently. It was thus important to carry out a similar study in Kenya to establish the level of efficiency and the factors that lead to high wastage of public resources in order to address this problem, especially within the frontline health facilities that serve the bulk of the Kenyan population. This study replicates the DEA results originally reported [22] in order to affirm that inefficiency is a major problem in frontline health facilities in county health systems so that the problem can be addressed by both Central and County Governments.

\section{Methodology}

\section{The DEA framework}

In a hospital where multiple inputs $X$ are used to produce multiple outputs $Y$

the technical efficiency of a decision making unit (DMU), such as a health centre can be expressed as:

$$
E_{o}=\frac{\sum_{i=1}^{r} U_{r} \cdot Y_{r j}}{\sum_{i=1}^{m} V_{i} \cdot X i j}
$$

Where:

$Y_{\mathrm{rj}}$ is the quantity of output $\mathrm{r}$ produced by unit $\mathrm{j}$

$U_{\mathrm{r}}$ is the weight attached to the output $\mathrm{r}$

$X_{\mathrm{ij}}$ is the quantity of input $\mathrm{i}$ used by unit $\mathrm{j}$

$V_{\mathrm{i}}$ is the weight attached to input $\mathrm{i}$

$E_{\mathrm{o}}$ is the hospital efficiency indicator which lies between 0 and 1

We then employ the linear programming techniques to get efficiency levels for each DMU.

At optimal productivity, output value will be exactly equal to input value according to a particular theorem of linear programming [18]. Efficiency is the productivity of a firm, which in this case is a health facility. Health facilities operating at optimal levels will have an efficiency score of unity, while those without any output will have an efficiency score of zero. Thus the efficiency score, $E_{0}$, lies within the range of zero and one:

$$
E_{o}=\frac{\sum_{i=1}^{r} U_{r} \cdot Y_{r j}}{\sum_{i=1}^{m} V_{i} \cdot X i j} \leq 1
$$

\section{Data}

The data set consists of all 17 DMUs (health facilities) located in one of the Meru sub-Counties [22]. Data were collected on inputs and outputs. The input data were collected on:

Clinical staff: This category of health personnel provide the first line of attention to patients, and are the most dominant in health facilities; they are also a powerful back up to doctors.

Other staff: These are the support staff that help in the general health facility operations, such as administration and health facility maintenance.

The data on health facility outputs were collected on:

Maternal care visits: these are for services related to prenatal care, postnatal care and family planning.

Other visits: these represent all other visits not related to maternal care. 


\section{Determinants of technical efficiency}

We compute technical efficiency scores and then use the Tobit regression due to [23] to explain variation in efficiency levels across health facilities. The efficiency scores are constrained to lie between zero and one [23-25]. We regress the technical efficiency scores on dummy variables that capture education, training, and gender of the facility manager and availability of a laboratory at a facility.

The stochastic model underlying the Tobit regression is of the form:

$y_{\mathrm{i}}^{*}=x_{\mathrm{i}} \beta+\varepsilon_{\mathrm{i}}$, where;

$y_{i}^{*}$ is the latent variable (technical efficiency) for the uncensored values between zero and one, and those censored from below if they are less than or equal to zero, and from above if they are greater or equal to one; $x_{\mathrm{i}} s$ are the observed values for all DMUs and $\beta s$ are parameters to be estimated. $\varepsilon_{\mathrm{i}}$ is the error term that is identically and independently distributed with mean zero and with a standard deviation, $\sigma^{2}$, i.e., $\left(\varepsilon_{\mathrm{i}}: N\left(0 \sigma^{2}\right)\right)$.

The observed technical efficiency score is defined by the equation:

$$
y_{i}=\left\{\begin{array}{l}
y_{i}^{*}=0 ; \text { if } y_{1}^{*} \leq 0 \\
y_{i}^{*}=x_{i} \beta+\varepsilon_{i} ; \text { if } y_{1}^{*} \varepsilon(01) \\
y_{i}^{*}=1 ; \text { if } y_{1}^{*} \geq 1
\end{array}\right.
$$

The model assumes existence of an underlying stochastic index equal to $x_{\mathrm{i}} \beta+\varepsilon_{\mathrm{i}}$, observed only if it lies within the conditions specified above.

\section{Results}

Table 1 presents descriptive statistics and the DEA results

\begin{tabular}{|c|c|c|c|c|c|}
\hline Variable & Obs & Mean & Std. Dev. & Min & Max \\
\hline \multicolumn{6}{|l|}{ Descriptive statistics } \\
\hline Maternal care visits & 17 & 937.5 & 723.5 & 16 & 2764 \\
\hline Clinical staff & 17 & 3.765 & 1.562 & 2 & 8 \\
\hline Nonclinical staff & 17 & 2.412 & 1.064 & 1 & 5 \\
\hline Education (1=college) & 17 & 0.588 & 0.507 & 0 & 1 \\
\hline Training (1=Yes) & 17 & 0.353 & 0.493 & 0 & 1 \\
\hline Gender (1=female) & 17 & 0.824 & 0.393 & 0 & 1 \\
\hline Laboratory (1=Yes) & 17 & 0.471 & 0.514 & 0 & 1 \\
\hline Other visits & 17 & 407.6 & 314.6 & 6.957 & 1202 \\
\hline DMUs & 17 & 9 & 5.05 & 1 & 17 \\
\hline \multicolumn{6}{|l|}{ DEA Scores } \\
\hline CRS TE & 17 & 0.452 & 0.299 & 0.016 & 1 \\
\hline VRS TE & 17 & 0.499 & 0.323 & 0.016 & 1 \\
\hline SCALE & 17 & 0.928 & 0.0967 & 0.747 & 1 \\
\hline
\end{tabular}

Table 1: Summary Statistics and DEA Estimates.

From Table 1 above, it can be seen that sample mean for clinical staff is 3.8. The most staffed DMU has 8 of them while the lowest has 2 which shows on average, there is poor distribution of staff across facilities. The maternal care visits distribution per DMU ranges from 16 to 2764 visits per month. The pattern of distribution of the work load across facilities has an effect on the technical efficiency levels observed. As can be seen from Table 1, there were a total of 17 DMUs, with an average technical efficiency scores ranging from 45-93 percent. That is, $45.2 \%$ (CRS score), $49.9 \%$ (VRS) and $92.8 \%$ (Scale). Thus, on average the DMUs operated at an inefficient level of $54.8 \%$ which suggests there is a lot of wastage and misallocation of the inputs supplied to health facilities by the county government. The results indicate the least efficient DMU is operating at an efficiency level of only $1.6 \%$. The power of DEA analysis is that such a facility can be identified and its efficiency level improved using specific measures informed by results from the Tobit regression analysis (see below).

\section{The Overall ranking of DMUs according to CRS technical efficiencies}

The overall ranking of the DMUs under the constant returns to scale (CRS) assumption show those two DMUs out of 17 (DMU6 and DMU7) are efficient, i.e., the scores for these DMUs lie on the efficient production frontier. These two health facilities are peers to themselves. They are efficiency reference points for all the other DMUs. From the analysis, it is noted that only eight DMUs are above the average efficiency score of $45.23 \%$. All the remaining DMUs fall far below this average. Furthermore, $88.24 \%$ of the DMUs were technically inefficient, as only $11.8 \%$ were operating efficiently. The technically inefficient DMUs need to put in measures to increase the level of the services they provide to patients. 


\section{Output targets and performance of health facilities}

Many DMUs in the sample did not achieve their output targets. For example DMU17 can increase its current output of 16 maternal care visits per month to the target of 979 and thus increase visits by 963 The number of other visits can similarly be increased by 425.7 . These examples show that there are large health benefits to be gained by improving efficiency of frontline health facilities.

\section{Determinants of technical efficiency}

In order to improve efficiency at health facilities, it is important to know why this performance metric varies across health facilities. Table 2 provides this information.

\begin{tabular}{|l|l|l|l|}
\hline Variable & CRS model 1 & VRS model 2 & Scale model 3 \\
\hline Education & -0.115 & -0.155 & 0.0903 \\
\hline & -0.14 & -0.153 & -0.0819 \\
\hline Training & -0.1 & -0.0919 & -0.0627 \\
\hline & -0.14 & -0.151 & -0.0918 \\
\hline Head nurse & $-0.451^{* *}$ & $-0.446^{* *}$ & -0.0898 \\
\hline & -0.183 & -0.199 & -0.111 \\
\hline Laboratory & 0.196 & $0.316^{* *}$ & $-0.295^{* * *}$ \\
\hline & -0.124 & -0.136 & -0.0865 \\
\hline Constant & $0.849^{* * *}$ & $0.867^{* * *}$ & $1.198^{* * *}$ \\
\hline & -0.223 & -0.243 & -0.148 \\
\hline Sigma & $0.250^{* * *}$ & $0.270^{* * *}$ & $0.103^{* * *}$ \\
\hline & -0.0474 & -0.0538 & -0.0305 \\
\hline Observations & 17 & 17 & 17 \\
\hline Note: ${ }^{* * *}=$ statistically significant at $5 \%$ & and $1 \%$, respectively. \\
\hline
\end{tabular}

Table 2: Determinants of technical efficiencies (S.E in parentheses).

The coefficient of the head nurse gender is statistically significant in the CRS and VRS models. The dispensaries and health centres that are managed by a female nurse or clinical officer are about $45 \%$ less efficient than the facilities that are managed by men. It is also evident from the table that facilities that have a laboratory are more efficient than the units that are not equipped with the capacity to diagnose diseases. The R2 (not shown in Table 2) indicates that $40.15 \%$ of the variation in efficiency score is due to changes in the variables included in the Tobit regression. It is worth noting that general education or training is uncorrelated to technical efficiency.

\section{Conclusion and Recommendation}

The study set out to establish the levels of technical efficiency and its determinants in public dispensaries and health centers in one of the Kenya's 47 County Governments. The study established that the frontline health facilities in Meru County had an efficiency level of $45.2 \%$. This efficiency score varied from $1.6 \%$ to $93 \%$, indicating that there is a lot of room in the county health system to improve service delivery. However, it should be noted that measures to improve efficiency require resources too. The facilities cannot improve their performance without spending money on things that enhance efficiency, such as training staff in better management practices, and maintenance of laboratory equipment. The results suggest that efficiency can be improved by changing gender composition of staff in the county health system. There is indirect evidence that creating awareness about the importance of preventive health care, such as regular check-ups to avoid incidences of severe illnesses that are difficult to treat would increase efficiency. It may also be necessary to invest in an environment in which patients can wait conveniently for treatment. Such investments can facilitate an orderly flow of queues of $p$ at ien ts within a health facility and enhance efficiency.

\section{Data Source}

A review of data collected from Meru County, Kenya.

\section{Data Synthesis}

Data collected from a sub-county in Meru County was used in this paper.

\section{Acknowledgement}

I wish to thank Professor G. Mwabu for giving me the data collected by Mr Eric Bundi for his MSc Research Paper at the University of Nairobi. This is an abridged version of my analytical paper written for a graduate course in microeconomic theory at the same university.

\section{References}

1. Noor AM, Alegana VA, Gething PW, Snow RW (2009) A spatial national health facility database for public health sector planning in Kenya in 2008. Intern J Health Geographics 8: 13.

2. Coelli TA (1996) A guide to DEAP version 2.1: a data envelopment analysis (computer) program. University of New England, Australia.

3. Kenya Government (2016) Kenya Healthcare sector, opportunities for the Dutch life Sciences and Health Sector.

4. Morse SS (1995). Factors in the Emergence of Infectious Diseases. Emerging Infectious Diseases. EID J 1: 1.

5. Cylus J, Papanicolas I, Smith PC (2017) Using Data Envelopment Analysis to Address the Challenges of Comparing Health System Efficiency. Global Policy 2: 60-68.

6. MOH (2014) Kenya Health Policy 2014-2030. Kenya government, Wiley online Library.

7. Nyamwange M (2012) Economic Growth and Public Healthcare Expenditure in Kenya (1982-2012). MPRA.

8. Gelband H, Panosian C, Arrow KJ (2004) Saving lives, buying time: economics of malaria drugs in an age of resistance. National Academies Press.

9. Bryan L, Conway M, Keesmaat T, McKenna S, Richardson B. (2010) Strengthening sub-Saharan Africa's health systems: a practical approach.

10. Palmer S, Torgerson DJ (1999) Economic notes: definitions of efficiency. BMJ 318: 1136.

11. Kirigia JM, Emrouznejad A, Cassoma B, Asbu EZ, Barry S (2008) A performance assessment method for hospitals: the case of municipal hospitals in Angola. J Med Sys 32: 509-519.

12. Needleman J, Hassmiller S (2009) The role of nurses in improving hospital quality and efficiency: real-world results. Health Affairs 28 .

13. Akazili J, Adjuik M, Jehu-Appiah C, Zere E (2008) Using data envelopment analysis to measure the extent of technical efficiency of public health centres in Ghana. BMC Int Health Hum Rights 8: 11. 
Citation: Makheti AJ (2017) Technical Efficiency in Public Health Facilities in Meru County: Dea Analysis. Health EconOutcome Res 3: 143.

14. Alhassan RK, Spieker N, van Ostenberg P, Ogink A, Nketiah-Amponsah E, et al. (2013) Association between health worker motivation and healthcare quality efforts in Ghana. BMC Human Resources for Health 11: 37 .

15. Carneiro CADS (2011) Essays on health economics: equity and access to health care and public hospital performance under corporatized management.

16. Akono ZC, Ndjokou MM (2013) Song-Ntamack S. Institutions and Hospital Efficiency in Cameroon: A Data Envelopment Analysis. J African Develop 15: 1

17. Alhassan RK, Amponsah E, Akazili J, Spieker N, Arhinful DK, et al. (2015) Efficiency of private and public primary health facilities accredited by the National Health Insurance Authority in Ghana. Cost Effectiveness and Resource Allocation 13: 1-23.

18. Green A, Mayes D (1991) Technical Inefficiency in Manufacturing Industries. The Econom J 101: 406.

19. Coelli TA (1996) guide to DEAP version 2.1: A Data Envelopment Analysis (Computer) Program. Centre for Efficiency and Productivity Analysis, University of New England, Australia.
20. Hollingsworth B (2003) Non-Parametric and Parametric Applications Measuring Efficiency in Health Care. Health Care Management Sci 6: 4.

21. Zere E, Mbeeli T, Shangula K, Mandlhate C, Mutirua K (2003) Technical Efficiency of District Hospitals: Evidence from Namibia using Data Envelopment Analysis. Cost Effectiveness and Resource Allocation 4: 1-5.

22. Bundi Eric (2016) Technical Efficiency in Public Health Dispensaries in Kenya: A Case Study of the Imenti-south Sub County, MSc Research Paper. School of Economics, University of Nairobi.

23. Tobin J (1958) Estimation of Relationships for Limited Dependent Variables. Econometrica: J the Econometric Society 26: 1.

24. McDonald JF, Moffitt RA (1980) The uses of Tobit analysis. The Review of Economics and Statistics 62: 2 .

25. Wei Wang, Griswold ME (2015) Natural interpretation in Tobit regression Models using Marginalised Methods. Statistical Methods Med Res 2015. 